\title{
The Predictive Value of the CRP-to-Albumin Ratio for Patients With Pancreatic Cancer After Curative Resection: A Retrospective Single Center Study
}

\author{
JOVAN VUJIC, KATHARINA MARSONER, VALERIE WIENERROITHER, \\ HANS-JORG MISCHINGER and PETER KORNPRAT \\ Division of General Surgery, Department of Surgery, Medical University of Graz, Graz, Austria
}

\begin{abstract}
Background/Aim: Prognostic factors like the CRP-to-albumin ratio (CAR) represent potential predictors for survival of pancreatic cancer patients. We aimed to investigate the prognostic strength of the CAR for overall survival of patients with pancreatic cancer undergoing pancreatic resection. Patients and Methods: Data from a total of 202 patients with pancreatic adenocarcinoma who had undergone curative pancreatic resection were subjected to a retrospective review. Overall survival was calculated according to the Kaplan-Meier method, and multivariate Cox regression analysis was used for calculating the prognostic strength of CAR. Results: CAR was an independent prognostic factor of overall survival in univariate and multivariate Cox regression analysis. Elevated CAR was associated with a higher median value of Charlson Index, higher Union for International Cancer Control (UICC) classification and increased carcinoembryonic antigen (CEA) levels. Conclusion: CAR is a useful prognostic factor for the prediction of overall survival for patients undergoing pancreatic surgery. The impact of CAR in individual risk assessment should be evaluated in further studies.
\end{abstract}

Pancreatic cancer represents three to four percent of all malignant tumors, but is responsible for approximately $6 \%$ of all cancer-related deaths in Austria. Every year, around 1,500 individuals are diagnosed with pancreatic cancer in Austria (1); pancreatic ductal adenocarcinoma (PDAC)

This article is freely accessible online.

Correspondence to: Peter Kornprat, Prof. MD, Division of General Surgery, Department of Surgery, Medical University of Graz, Auenbruggerplatz 29, 8036 Graz, Austria. Tel: +43 31638580524, Fax: +43 31638514666, e-mail: peter.kornprat@medunigraz.at

Key Words: C-reactive protein, albumin, pancreatic adenocarcinoma, surgery, CAR. presents in general at a median age of 70 years (2). One of the factors that contributes to this high mortality rate is the fact that most cases are detected in an advanced tumor stage. The factors that contribute to genesis of pancreatic cancer are heredity, lifestyle, smoking, alcohol usage, obesity, diabetes, chronic pancreatitis, and increased use of industrial chemical substances (3-5). Inflammatory processes have been shown to be key mediators of the development and progression of pancreatic cancer (6-8). Furthermore, there is novel evidence that intracellular accumulation in perisinusoidal cells in the liver can lead to activation of carcinogenic development in genetically predisposed individuals (8). Systemic inflammatory reactions play an important role in carcinogenesis and tumor progression (9).

CAR (CRP-to-albumin ratio) is related to tumor-free survival and the overall outcome of cancer patients $(10,11)$, but its role in patients with pancreatic ductal adenocarcinoma (PDA) undergoing pancreatic resection has been investigated only in a few reports $(12,13)$. At this point, there is no inflammation-based score predicting outcome in patients with PDAC after surgical resection.

Our main goal was to determine if CAR could represent a useful prognostic factor for the outcome of patients diagnosed with PDAC.

\section{Patients and Methods}

This retrospective study was conducted as a single-center-analysis at the division of general surgery of the Medical University of Graz. All data from patients with resectable PDA that underwent pancreatic surgery between January 2000 and December 2016 at our department were included (202 patients). This study included only the patients with diagnosed PDAC. Patients who died within thirty days after tumor resection as well as patients with missing data were excluded from the study ( 84 patients). Patient selection is shown in Figure 1. TNM categories were taken from the American Joint Committee on Cancer (AJCC) tumor/node/metastasis (TNM) classification and staging system for pancreatic cancer (Eighth 


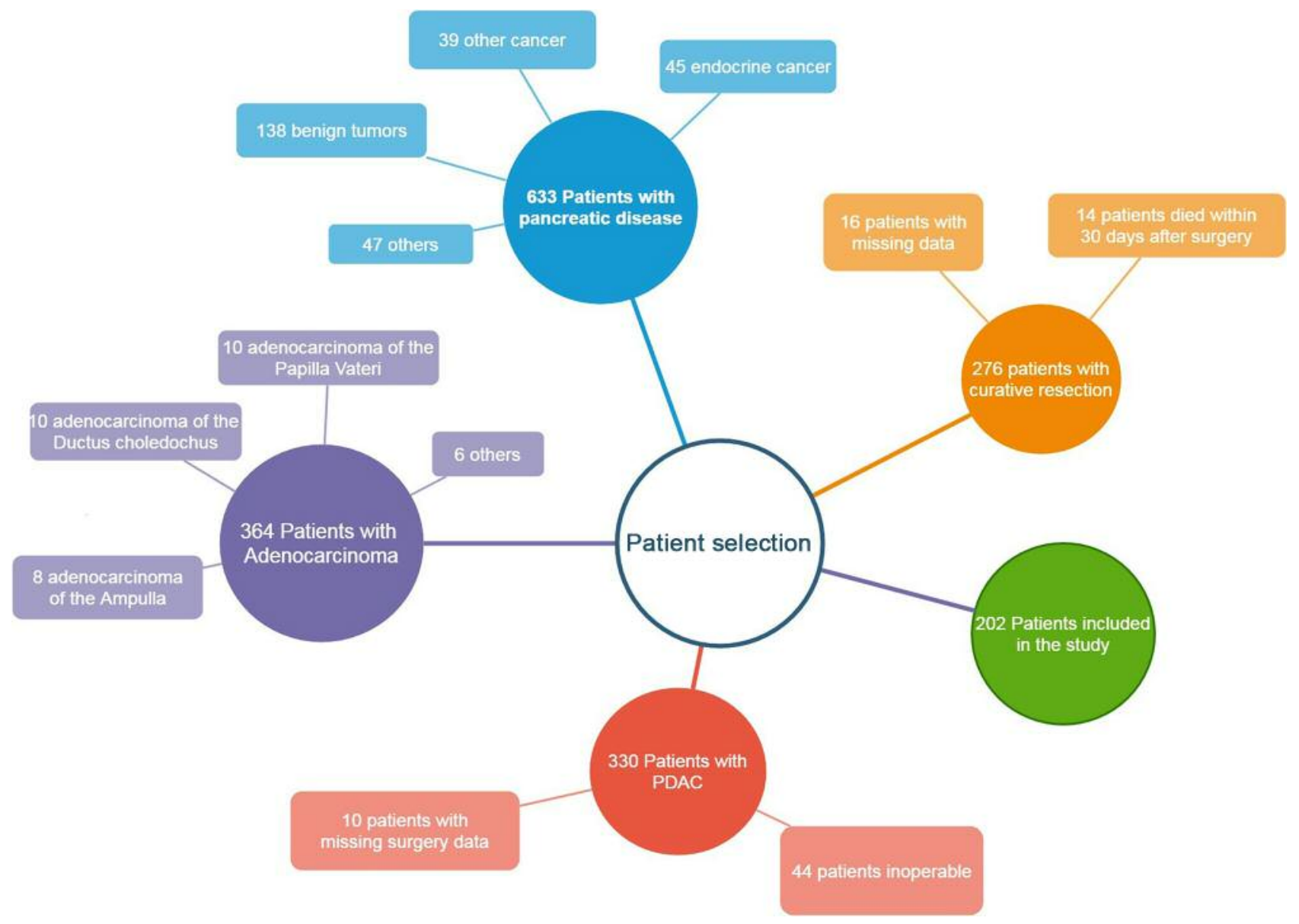

Figure 1. Selection of patients in the study.

Edition 2017). Outcome variables were collected from the patient's medical history and the Austrian national cancer registry.

The patient collective was categorized by different factors, including ASA category (14) and the Charlson comorbidity index (15).

Data collection. Patient data were retrospectively obtained from the digital clinical database "Medocs". The data were anonymized and collected in an excel spreadsheet. The following clinical and pathological parameters were obtained: Baseline variables, such as preoperative symptoms, risk factors and comorbidities, preoperative laboratory values, peri-, intra- and postoperative data, histopathologic data as well as follow-up details. The study protocol was approved by the local ethics committee (25-303 ex 12/13).

Statistics. Statistical analysis was performed with SPSS 240 for windows (IBM Inc. Somers, USA). For categorical data, chi square test was conducted, while for numeric data $t$-test or Mann-Whitney $\mathrm{U}$ test were performed as appropriate. Univariate and multivariate analysis was performed using COX regression analysis to assess the influence of the different clinical-pathological parameters on overall survival. A two-sided $p<0.05$ was considered as statistically significant.
Overall survival as well as tumor-free survival were calculated according to the Kaplan-Meier method.

\section{Results}

The cut-off value for the CAR for this patient collective was 0.0003 . Figure 2 shows the Kaplan-Meier curve for patients with a CAR $<0.0003$ (blue, 143 patients) vs. patients with a CAR >0.0003 (green, 59 patients). In Figure 3 the KaplanMeier curves for increased serum CRP and hypoalbuminemia are shown. The cut-off value of $9.77 \mathrm{mg} / 1$ for CRP was obtained with ROC analysis. Compared to CAR, the two factors alone did not show a significant influence on patient's collective overall survival (CRP$p=0.103$, albumin $p=0.091$ for $p<0.05$ ).

The mortality figure (Figure 4) shows a significant difference between patients with a CAR $<0.0003$ and patients with a $C A R>0.0003$. The one-year survival of patients with a $\mathrm{CAR}<0.0003$ was $67 \%$ while patients with $\mathrm{CAR}>0.0003$ had one-year survival of $56 \%$. The five-year survival of 


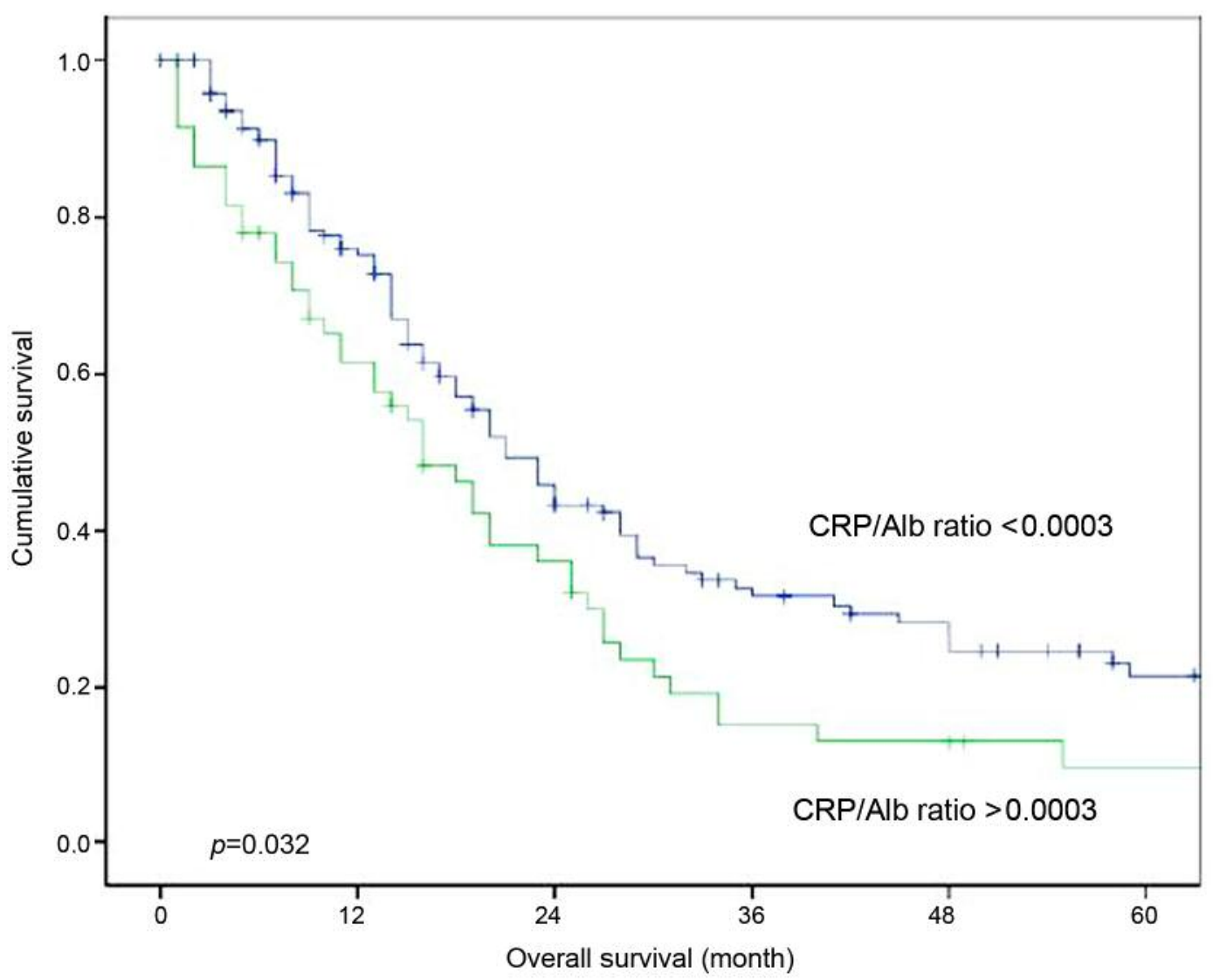

Figure 2. Cumulative survival in patients with a CAR $>0.0003$ (green) vs. patients with a CAR $<0.0003$ (blue). Overall survival time ( $p=0.032$ ) was significantly lower in patients who had higher CAR.

patients with $\mathrm{CAR}<0.0003$ ratio was $7 \%$ and that of patients with a CAR $>0.0003$ was $3 \%$. As shown in Table I, patients with a CAR $>0.003$ have a significantly shorter overall survival time (15.3 months) compared to patients with a CAR $<0.0003$ (21.2 months, $p=0.021)$. It was also shown, that patients with a CAR $>0.0003$ have longer in-hospital stay than patients with a CAR $<0.0003(p=0.019)$. There was no difference between the two groups regarding age, followup time, carbohydrate antigen (CA) 19-9 or CEA.

The occurrence of preoperative symptoms- jaundice and pancreatitis- correlated with a CAR $>0.0003$. Age $>70$, female sex, Charlson Index $>2$, the incidence of morbidity after surgery (operation-related complications), a CA 19-9>37 kIU/l, a higher grading, or distant metastasis were not correlated with CAR $>0.0003$ (Table II). Table III shows the results of univariate analysis of factors influencing overall survival; metastasis, lymph node involvement and CAR $>0.0003$ were associated with overall survival. There was no significant difference for serum albumin levels, CRP levels, age, age $>70$, Sex, R-category, grading, Charlson index, the occurrence of preoperative symptoms, CEA levels or CA 19-9 levels.
Table IV shows the multivariate analysis of $\mathrm{M}$ category, higher grading, CAR $>0.0003$ and the presence of preoperative pancreatitis. It was shown that CAR $>0.0003$, grading, $M$ category and preoperative pancreatitis were associated with overall survival in multivariate analysis.

\section{Discussion}

Although pancreatic cancer represents a non-frequent tumor type comprising around four percent of all cancer cases, it is associated with low long-term survival. Up to now, complete surgical resection of the pancreatic tumor still represents the only curative therapeutic approach, but numerous patients are still diagnosed at a non-resectable tumor stage. After surgical resection, the five-year tumor-free survival is reportedly only $25 \%(2,5,7)$.

In most cases of pancreatic cancer, one of the most commonly used diagnostic tests for detection, resectability criteria, prognosis and response to therapy of PDA patients are serum levels of CA19-9. Sensitivity of CA19-9 serum levels is low because of false positive results, for example in the presence of biliary stasis. However, it still remains one 

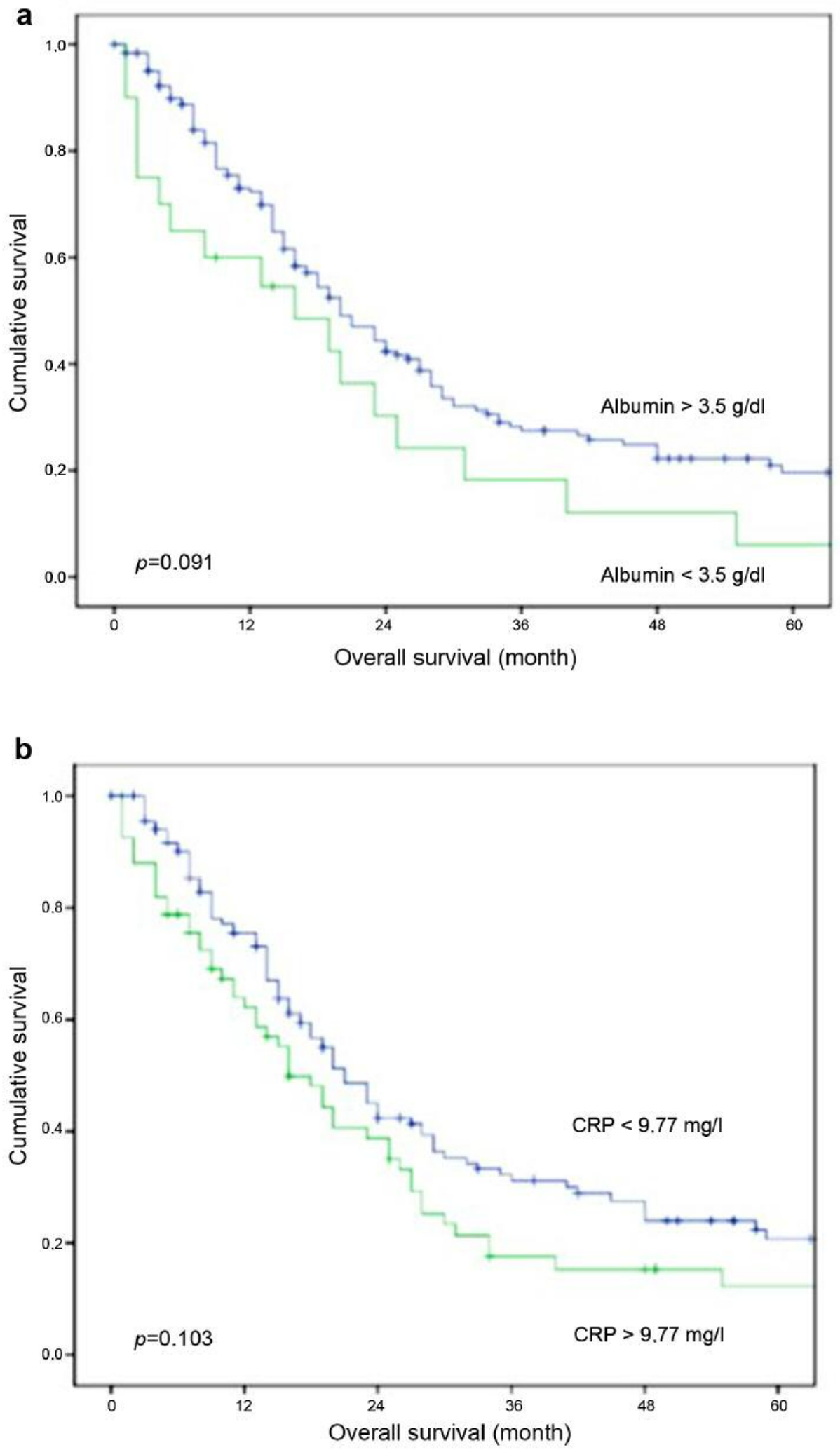

Figure 3. Cumulative survival a) for patients with a serum albumin $<3.5 \mathrm{~g} / \mathrm{dl}$ (green) vs. patients with a serum albumin $>3.5 \mathrm{~g} / \mathrm{dl}$ (blue), $p=0.091$ b) for patients with a serum $C R P>10$ (green) vs. patients with a serum $C R P<9.77 \mathrm{mg} / \mathrm{l}, p=0.103$. It is shown that the combination of the factors and not each factor alone, shows influence on follow-up time. 


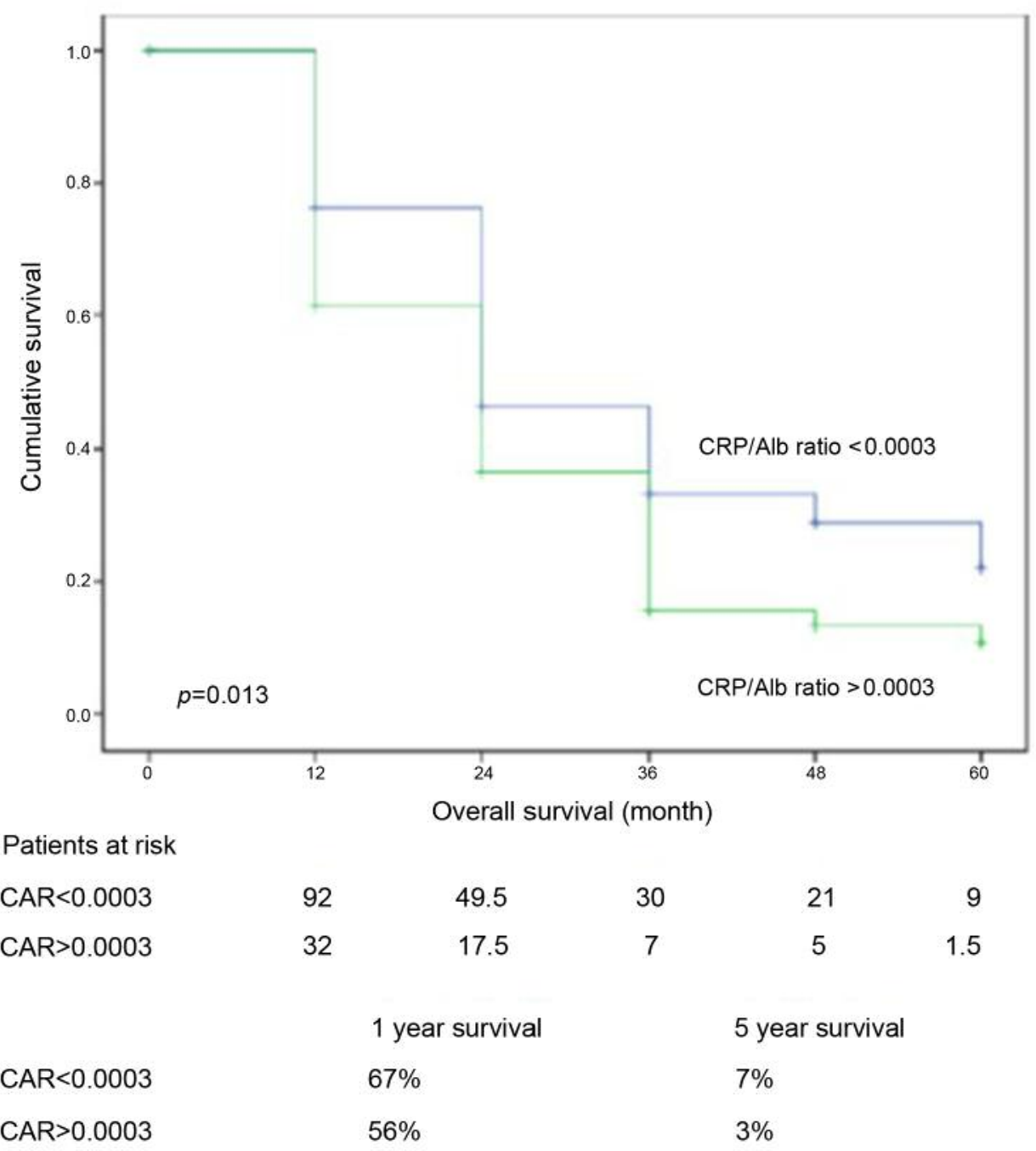

Figure 4. Mortality of patients with $C A R<0.0003$ vs. patients with $C A R>0.0003$.

of the most common prognostic indicators in patients suffering from PDAC (5).

We assessed the prognostic value of CAR in patients who had undergone pancreatic resection. CRP is synthesized by hepatocytes and its production is stimulated by proinflammatory cytokines, especially interleukin 6 . Research states that inflammatory processes within the tumor activate systematic inflammatory pathways which are detectable and could be related to tumor prognosis and outcome $(13,16-27)$. The CAR has been described as a strong predictive factor for overall survival of other tumor types, such as intrahepatic cholangiocarcinoma, liver, lung and gastric cancer $(10,18$, $22,23)$. For advanced pancreatic cancer, statistical analysis (17) revealed that the optimal cut-off value for CAR was 0.54 ; patients with a CAR $>0.54$ showed an overall shorter survival time (5.0 vs. 2.9 month; $p=0.002)$, which is in line with the results of found by Wu et al. (19).

For patients who underwent curative pancreatic resection, Haruki et al. (12) has proposed an optimal cut-off value of 0.03 . Patients with a CAR $>0.03$ showed a shorter disease-free survival and a decreased survival time in our study population. Compared to Wu et al. (19) and Haruki et al. (12) this cut-off value seems small, but with the correct conversion factor from $\mathrm{mg} / \mathrm{l}$ (CRP) to $\mathrm{g} / \mathrm{dl}$ (albumin) and an average CRP of $15.8 \mathrm{mg} / \mathrm{dl}$, the CAR values were comparable. According to Wu et al. and Haruki et al., we could demonstrate that patients with a higher CAR had significantly lower median survival time (21.2 vs. 15.3 months; $p=0.021)$.

Ikuta et al. (13) have reported greater difference in median overall survival time in patients with higher and lower CAR 
Table I. Univariate analysis of clinical and pathological parameters in patients with $C A R>0.0003$ vs. patients with $C A R<0.0003$.

\begin{tabular}{lccl}
\hline Parameter & $\begin{array}{c}\text { CAR }<0.0003 \\
\text { mean }\end{array}$ & $\begin{array}{c}\text { CAR }>0.0003 \\
\text { mean }\end{array}$ & $p$-Value \\
\hline Age & 65.1 & 65.1 & 0.962 \\
Survival (months) & 21.2 & 15.3 & $0.021^{*}$ \\
Follow-up (months) & 24.9 & 19.6 & 0.115 \\
Hospital stay (days) & 11.3 & 15.7 & $0.019^{*}$ \\
CA 19-9 [kIU/l] & 787.8 & 2248.9 & 0.339 \\
CEA [ $\mu \mathrm{g} / \mathrm{l}]$ & 4.6 & 7.9 & 0.254 \\
\hline
\end{tabular}

CEA: Carcinoembryonic antigen; CA 19-9: carbohydrate antigen.

Table II. Univariate analysis (Chi-square test) of clinical and pathological parameters in patients with $C A R<0.0003$ or $C A R>0.0003$.

\begin{tabular}{lccl}
\hline Parameter & $\begin{array}{c}\text { CAR }<0.0003 \\
\mathrm{n}[\%]\end{array}$ & $\begin{array}{c}\mathrm{CAR}>0.0003, \\
\mathrm{n}[\%]\end{array}$ & $p$-Value \\
\hline Age $>70$ & $55[27 \%]$ & $18[9 \%]$ & 0.285 \\
Female & $67[33 \%]$ & $32[16 \%]$ & 0.34 \\
Charlson Index>2 & $72[36 \%]$ & $40[20 \%]$ & $0.026^{*}$ \\
Morbidity & $35[17 \%]$ & $11[5 \%]$ & 0.425 \\
UICC IIB/III/IV & $114[56 \%]$ & $54[27 \%]$ & $0.041^{*}$ \\
Preoperative Symptoms & $81[43 \%]$ & $46[25 \%]$ & $0.0001^{*}$ \\
Pancreatitis & $11[6 \%]$ & $11[6 \%]$ & $0.019^{*}$ \\
Jaundice & $38[19 \%]$ & $33[17 \%]$ & $0.0001^{*}$ \\
Weight loss & $29[15 \%]$ & $20[10 \%]$ & $0.044^{*}$ \\
\hline
\end{tabular}

$p<0.05^{*}, p<0.01 * *, p<0.001 * * *$.

(17.0 months $v s .30 .2$ months; $p=0.01$ ). They also reported that the CAR correlates with poor outcome in cox regression analysis.

Kaplan-Meier analysis of our cohort, indicated that CRP and albumin alone were not associated with worse outcome (a: $p=0.091$, b: $p=0.103$ ). According to this, serum levels of CRP alone did not correlate with overall survival in univariate Cox regression analysis. Further research is warranted to confirm the hypothesis that CAR is superior to CRP serum levels alone in patients risk stratification. We could show that a CAR $>0.0003$ was associated with a longer in-hospital stay (11.3 vs. 15.7 days; $p=0.019$ ), a higher UICC stage, a Charlson Index $>2$ and presence of preoperative symptoms, especially jaundice, weight loss and preoperative pancreatitis which are clinical surrogate parameters for advanced disease. Nevertheless, age, gender, tumor stage, tumor localization or CA 19-9 levels were not correlated with elevated CAR levels in uni- and multivariate analysis. In our study, CAR was shown to be statistically significant in both univariate and
Table III. Univariate analysis of different parameters related to overall survival.

\begin{tabular}{lccc}
\hline Parameter & Median & Odds ratio $(95 \% \mathrm{CI})$ & $p$-Value \\
\hline CAR $>0.003$ & & $1.454(1.024-2.063)$ & $0.036^{*}$ \\
CRP $[\mathrm{mg} / \mathrm{dl}]$ & \multirow{2}{*}{15.6} & $1.003(1.001-1.008)$ & 0.348 \\
CRP $>10 \mathrm{mg} / \mathrm{dl}$ & & $1.325(0.939-1.870)$ & 0.109 \\
Albumin $[\mathrm{g} / \mathrm{dl}]$ & \multirow{2}{*}{4.0} & $0.923(0.714-1.193)$ & 0.539 \\
Albumin $<3.5 \mathrm{~g} / \mathrm{dl}$ & & $1.534(0.924-2.546)$ & 0.098 \\
CA $19-9[\mathrm{kU} / \mathrm{l}]$ & \multirow{2}{*}{1816.6} & $1.00(1.00-1.00)$ & 0.643 \\
CA $19-9>37 \mathrm{kU} / 1$ & & $1.200(0.791-1.821)$ & 0.392 \\
CEA $[\mathrm{ng} / \mathrm{ml}]$ & \multirow{2}{*}{5.7} & $1.003(0.992-1.013)$ & 0.600 \\
CEA $>3.8 \mathrm{ng} / \mathrm{ml}$ & & $0.873(0.582-1.310)$ & 0.513 \\
Age & \multirow{2}{*}{65.1} & $1.005(0.988-1.023)$ & 0.553 \\
Age $>70$ & & $0.955(0.804-1.134)$ & 0.955 \\
Sex & & $1.177(0.847-1.636)$ & 0.332 \\
UICC IIB/III/IV & & $2.757(1.623-4.682)$ & $0.0001^{*}$ \\
\hline
\end{tabular}

$p<0.05^{*}, p<0.01 * *, p<0.001 * * *$.

Table IV. Multivariate analysis (cox regression analysis) of parameters which were significantly correlated with the overall survival time in univariate analysis.

\begin{tabular}{lcc}
\hline & Odds Ratio $(95 \% \mathrm{CI})$ & $p$-Value \\
\hline Grading 3/4 & $1.728(1.225-2.439)$ & $0.002^{*}$ \\
Preop. Pancreatitis & $1.739(1.073-2.819)$ & $0.025^{*}$ \\
M-Category 1 & $1.553(1.018-2.370)$ & $0.041^{*}$ \\
CAR $>0.0003$ & $1.459(1.009-2.108)$ & $0.045^{*}$ \\
\hline
\end{tabular}

$p<0.05^{*}, p<0.01^{* *}, p<0.001^{* * *}$.

multivariate analysis. Multivariate analysis showed that patients with a CAR $>0.0003$, metastasis, preoperative pancreatitis and a higher grade had a poor overall survival.

There are limitations and strengths to this study. It holds the known disadvantages of a retrospective single center analysis; nevertheless, our results show a clear association between CAR levels and long-term outcome after pancreatic cancer surgery in our patient cohort.

CAR is an easily available independent predictive factor for survival in patients undergoing curative pancreatic surgery. More extensive research with prospective randomized design is warranted to evaluate the prognostic value of CAR and its optimal cut-off point in patients undergoing pancreatic cancer surgery.

\section{Conflicts of Interest}

The Authors do not have any conflicts of interest to declare regarding this study. 


\section{Authors' Contributions}

K.P, M.H-J and M.K, J.V conceived and designed the study; K.P., M.H-J, M.K performed the study; W.V and K.P, V.J, M.H-J, M.K. recruited patients, collected and processed samples; and V.J. and W.V. contributed reagents/materials/analysis tools; and V.J, M.K. and K.P. wrote the article. All Authors declare they significantly participated in creation of the study. All Authors read and approved the final article.

\section{References}

1 Statistik Austria. Krebserkrankungen in Österreich 2018 Available at: file://C:/Users/Korisnik/Desktop/ACR\%20UM FORM/krebserkrankungen_in_oesterreich_2018.pdf (Last accessed on 23rd July 2019)

2 Bekkali NL and Oppong KW: Pancreatic ductal adenocarcinoma epidemiology and risk assessment: Could we prevent? Possibility for an early diagnosis. Endosc Ultrasound 6: S58-61, 2017. PMID: 29387690. DOI: 10.4103/eus.eus_60_17

3 Kirkegård J, Mortensen FV and Cronin-Fenton D: Chronic pancreatitis and pancreatic cancer risk: A systematic review and meta-analysis. Am J Gastroenterol advance online publication August 112(9): 1366-1372, 2017. PMID: 28762376. DOI: 10.1038/ajg.2017.218

4 Kirkegård J, Cronin-Fenton $\mathrm{D}$, Heide-Jørgensen $\mathrm{U}$ and Mortensen FV: Acute pancreatitis and pancreatic cancer risk: A nationwide matched-cohort study in Denmark. Gastroenterology 154: 1729-1736, 2018. PMID: 29432727. DOI: 10.1053/ j.gastro.2018.02.011

5 Hao L, Zeng PX, Xin L, Wang D, Pan J, Bi YW, Ji JT, Du TT, Lin JH, Zhang D, Ye B, Zou WB, Chen H, Xie T, Li ZS and Hu LH: Incidence of and risk factors for pancreatic cancer in chronic pancreatitis: A cohort of 1656 patients. Dig Liver Dis 49(11): 1249-1256, 2017. PMID: 28756974. DOI: 10.1016/ j.dld.2017.07.001

6 Kaplan M, Ates I, Akpinar MY, Yuksel M, Kuzu UB, Kacar S, Coskun $\mathrm{O}$ and Kayacetin E: Predictive value of C-reactive protein/albumin ratio in acute pancreatitis. Hepatobiliary Pancreat Dis Int 16(4): 424-430, 2017. PMID: 28823374. DOI: 10.1016/S1499-3872(17)60007-9

7 Shadhu K and Xi C: Inflammation and pancreatic cancer: An updated review. Saudi J Gastroenterol 25: 3-13, 2019. PMID: 30588953. DOI: 10.4103/sjg.SJG_390_18

8 Padoan A, Plebani M and Basso D: Inflammation and pancreatic cancer: Focus on metabolism, cytokines, and immunity. Int J Mol Sci 20(3): E676, 2019. PMID: 30764482. DOI: 10.3390/ijms20030676

9 Dzutsev A, Goldszmid RS, Viaud S, Zitvogel L and Trinchieri $\mathrm{G}$ : The role of the microbiota in inflammation, carcinogenesis, and cancer therapy. Eur J Immunol 45: 17-31, 2015. PMID: 25328099. DOI: $10.1002 /$ ji.201444972

10 Kinoshita A, Onoda H, Imai N, Iwaku A, Oishi M, Tanaka K, Fushiya N, Koike K, Nishino H and Matsushima M: The Creactive protein/albumin ratio, a novel inflammation-based prognostic score, predicts outcomes in patients with hepatocellular carcinoma. Ann Surg. Oncol 22: 803-810, 2015. PMID: 25190127. DOI: 10.1245/s10434-014-4048-0

11 Park HC, Kim MY and Kim CH: C-reactive protein/albumin ratio as prognostic score in oral squamous cell carcinoma. J
Korean Assoc. Oral Maxillofac Surg 42: 243-250, 2016. PMID: 27847731. DOI: $10.5125 /$ jkaoms.2016.42.5.243

12 Haruki K, Shiba H, Shirai Y, Horiuchi T, Iwase R, Fujiwara Y, Furukawa K, Misawa T and Yanaga K: The C-reactive protein to albumin ratio predicts long-term outcomes in patients with pancreatic cancer after pancreatic resection. World J Surg 40: 2254-2260, 2016. PMID: 26956901. DOI: 10.1007/s00268-0163491-4

13 Ikuta S, Tsukasa A and Yamanaka N: Preoperative C-reactive protein to albumin ratio is a predictor of survival after pancreatic resection for pancreatic ductal adenocarcinoma. Asia Pac J Clin Oncol, 2019. PMID: 30632282. DOI: 10.1111/ajco.13123

14 Fitz-Henry J: The ASA classification and peri-operative risk. Ann R Coll Surg Engl 93(3): 185-187, 2011. PMID: 21477427. DOI: $10.1308 /$ rcsann.2011.93.3.185a

15 Hall WH, Ramachandran R and Vijayakumar S: An electronic application for rapidly calculating Charlson comorbidity score. BMC Cancer 20(4): 94, 2004. PMID: 15610554. DOI: 10.1186/1471-2407-4-94

16 Hausmann S, Kong B, Michalski C, Erkan M and Friess H: The role of inflammation in pancreatic cancer. Adv Exp Med Biol 816: 129-151, 2014. PMID: 24818722. DOI: 10.1007/978-30348-0837-8_6

17 Liu Z, Jin K, Guo M, Long J, Liu L, Liu C, Xu J, Ni Q, Luo G and $\mathrm{Yu} X$ : Prognostic value of the $\mathrm{CRP} / \mathrm{alb}$ ratio, a novel inflammation-based score in pancreatic cancer. Ann Surg Oncol 24: 561-568, 2017. PMID: 27650825. DOI: 10.1245/s10434016-5579-3

18 Toiyama Y, Shimura T, Yasuda H, Fujikawa H, Okita Y, Kobayashi M, Ohi M, Yoshiyama S, Hiro J, Araki T, Inoue Y, Mohri Y and Kusunoki M: Clinical burden of C-reactive protein/albumin ratio before curative surgery for patients with gastric cancer. Anticancer Res 36(12): 6491-6498, 2016. PMID: 27919972. DOI: 10.21873/anticanres.11248

$19 \mathrm{Wu}$ M, Guo J, Guo L and Zuo Q: The C-reactive protein/albumin ratio predicts overall survival of patients with advanced pancreatic cancer. Tumour Biol 37: 12525-12533, 2016. PMID: 27344157. DOI: 10.1007/s13277-016-5122-y

20 Hang J, Xue P and Wang L: Pretreatment C-reactive protein to albumin ratio for predicting overall survival in advanced pancreatic cancer patients. Sci Rep 7: 2993, 2017. PMID: 28592881. DOI: $10.1038 / \mathrm{s} 41598-017-03153-6$

21 Argilés JM, Busquets S and López-Soriano FJ: Cytokines in the pathogenesis of cancer cachexia. Curr Opin Clin Nutr Metab Care 6: 401-406, 2003. PMID: 12806213. DOI: 10.1097/ 01.mco.0000078983.18774.cc

22 Nakao Y, Yamashita YI, Arima K, Miyata T, Itoyama R, Yusa T, Umezaki N, Yamao T, Nakagawa S, Okabe H, Imai K, Chikamoto A and Baba H: Clinical usefulness of perioperative c-reactive protein/albumin ratio in patients with intrahepatic cholangiocarcinoma: A retrospective single institutional study. Anticancer Res 39(5): 2641-2646, 2019. PMID: 31092463. DOI: 10.21873/anticanres. 13388

23 Forrest LM, McMillan DC, McArdle CS, Angerson WJ and Dunlop DJ: Evaluation of cumulative prognostic scores based on the systemic inflammatory response in patients with inoperable non-small-cell lung cancer. Br J Cancer 89: 10281030, 2003. PMID: 12966420. DOI: 10.1038/sj.bjc.6601242

24 Ranzani OT, Zampieri FG, Forte DN, Azevedo LC and Park M: $\mathrm{C}$-reactive protein/albumin ratio predicts 90 -day mortality of 
septic patients. PLoS One 8: e59321, 2013. PMID: 23555017. DOI: 10.1371 /journal.pone.0059321

25 Kim MH, Ahn JY, Song JE,Choi H, Ann HW, Kim JK, Kim JH, Jeon YD, Kim SB, Jeong SJ, Ku NS, Han SH, Song YG, Choi JY, Kim YS and Kim JM: The C-reactive protein/albumin ratio as an independent predictor of mortality in patients with severe sepsis or septic shock treated with early goal-directed therapy. PLoS One 10: e0132109, 2015. PMID: 26158725. DOI: 10.1371/journal.pone.0132109

26 Karin M: Nuclear factor-kappaB in cancer development and progression. Nature 441: 431-436, 2006. PMID: 16724054. DOI: $10.1038 /$ nature 04870
27 Lee JM, LeeHS, Hyun JJ, Choi SH, Kim SE, Keum B, Seo SY, Jeen TY, Chun JH, Um HS and Kim DC: Prognostic value of inflammation-based markers in patients with pancreatic cancer administered gemcitabine and erlotinib. World J Gastrointest Oncol 8: 555-562, 2016. PMID: 27559435. DOI: 10.4251/ wjgo.v8.i7.555

Received July 23, 2019

Revised September 11, 2019

Accepted September 13, 2019 